\title{
Respiratory distress due to tracheal compression by the dilated innominate artery
}

\author{
E. Sato", S. Koyama\#, H. Kamijyo*, O. Kobayashi*, M. Terashima*, K. Kubo
}

Respiratory distress due to tracheal compression by the dilated innominate artery. E. Sato, S. Koyama, H. Kamijyo, O. Kobayashi, M. Terashima, K. Kubo. (C)ERS Journals Ltd 1999. ABSTRACT: The case reported is of an $88 \mathrm{yr}$ old female with hypertension and respiratory distress. A chest radiograph revealed a widening of the upper mediastinum. Computed tomographic scanning revealed tracheal compression by the innominate artery, which was elongated and curved. After intubation, she was treated with antihypertensive drugs. This resulted in the remarkable recovery of the patient from respiratory distress. To the authors' knowledge, this is the first reported case of respiratory distress owing to tracheal compression by elongation and curvature of the innominate artery.

Eur Respir J 1999; 14: 723-724.

Tracheal obstruction causing respiratory distress can be caused by neoplasms $[1,2]$, as well as external compression from arterial aneurysms [3-5] and a vascular ring [6]. When the compression in the tracheal tract becomes severe, patients develop respiratory distress. The following is a report of a case of respiratory distress owing to tracheal compression by elongation and curvature of the innominate artery.

\section{Case report}

An 88 yr-old female was admitted to the authors' hospital complaining of dyspnoea and cough. She was previously diagnosed as having bronchial asthma, and medication was occasionally prescribed. She had been hypertensive and had atrial fibrillation for $>10 \mathrm{yrs}$, but there was no history suggestive of cardiac failure. Two days before admission she complained of cough and exertional dyspnoea. Her symptoms worsened, and she consulted the authors' emergency clinic on January 23 , 1998.

Upon physical examination, her heart rate was irregular at 100 beats $\cdot \mathrm{min}^{-1}$, blood pressure was $224 / 120 \mathrm{mmHg}$, and body temperature was $37.0^{\circ} \mathrm{C}$. Auscultation of heart sounds revealed systolic regurgitant murmur. Wheezing was audible on the neck, but no rales were detected in either lung. Analysis of arterial blood gases revealed a $\mathrm{pH}$ of 7.41 , arterial oxygen tension $\left(\mathrm{Pa}_{2} \mathrm{O}_{2}\right) 9.2 \mathrm{kPa}(69$ $\mathrm{mmHg})$, and arterial carbon dioxide tension $\left(\mathrm{Pa}_{\mathrm{a}} \mathrm{CO}_{2}\right) 5.3$ $\mathrm{kPa}(40.2 \mathrm{mmHg})$. Laboratory analysis of blood revealed haemoglobin $129 \mathrm{~g} \cdot \mathrm{L}^{-1}$, haematocrit $39 \%$, and white blood cell count 6.250 cells $\cdot \mu \mathrm{L}^{-1}$, with $54.8 \%$ neutrophils, $2.4 \%$ eosinophils, $6.4 \%$ monocytes, and $34.5 \%$ lymphocytes. Creactive protein (CRP) was $0.2 \mathrm{mg} \cdot \mathrm{L}^{-1}$.

\begin{abstract}
"First Dept of Internal Medicine, Shinshu University School of Medicine, Matsumoto, Japan. *Iiyama Red Cross Hospital, Iiyama, Japan.

Correspondence: S. Koyama The First Dept of Internal Medicine Shinshu University School of Medicine 3-1-1 Asahi Matsumoto 390 Japan Fax: 81263363722

Keywords: Arterial elongation, tracheal compression, tracheal stenosis

Received: June 131998

Accepted after revision December 31998
\end{abstract}

A chest radiograph revealed a widening of the upper mediastium and cardiomegaly (fig. 1). Bronchoscopy showed a narrowing, with pulsatile compression at the upper portion of the trachea. Computed tomography of the chest demonstrated elongation of the innominate artery, which compressed the upper portion of the trachea (fig. 2).

The patient was endotracheally intubated and put on a respirator, and showed remarkable improvement. No wheezing was heard on examination. She was treated with antihypertensive drugs. On the third day after admission, she was weaned from the ventilator, and was discharged on the 10th day. Her symptoms remained stable over the following 2 months with a treatment aimed at optimal blood pressure control.

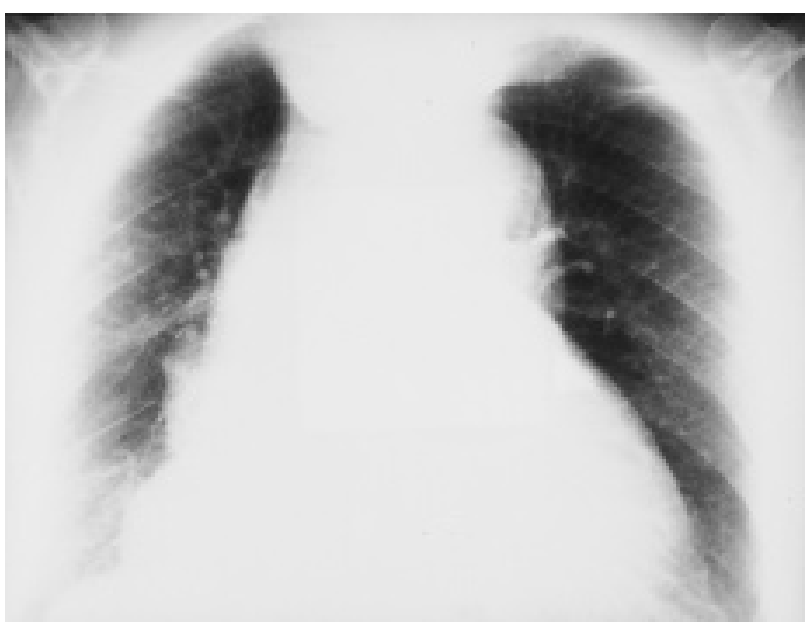

Fig. 1. - Chest radiograph showing widening of the upper mediastinum and cardiomegaly. 


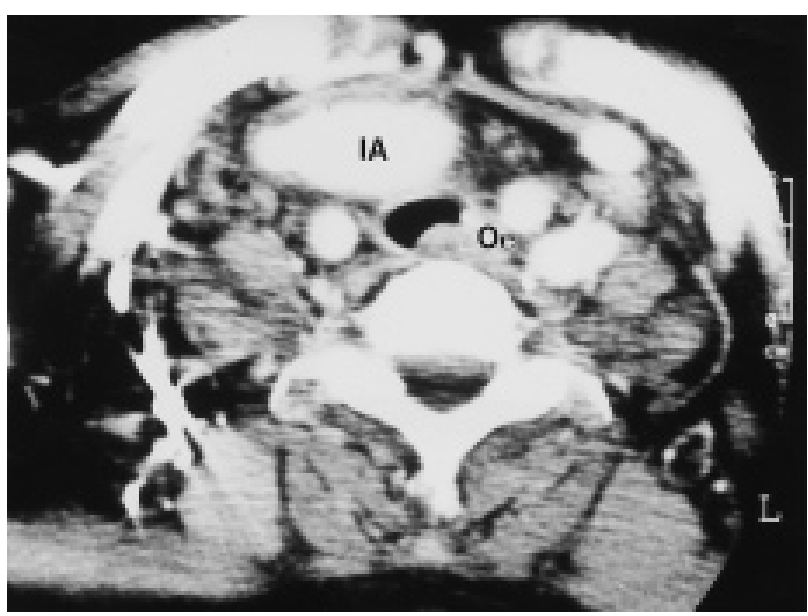

Fig. 2. - Enhanced computed tomographic scan of the chest demonstrating tracheal compression by the innominate artery (IA). Oe: oesophagus.

\section{Discussion}

Acute respiratory distress with tracheal obstruction owing to extrinsic compression has been reported in patients with aneurysms of the aorta and vascular anomalies, including a vascular ring. Some of these were also in conjunction with dilatation of the brachiocephalic artery [3]. Severe tracheal compression by the aneurysm of the ascending aorta has also been described $[4,5]$. Two further cases of fatal acute laryngeal compression by the haematomas following rupture of thoracic aortic aneurysms have been reported [7]. However, respiratory distress owing to compression of the trachea by the innominate artery without aneurysm has not to the authors' knowledge been described previously.

Because the compression of the trachea by the innominate artery appeared to be a result of the hypertension, the patients' blood pressure was corrected. The patient had no recurrence of respiratory distress during the 2 months of follow-up. Considering the patient's age and condition, surgical intervention would have been hazardous. However, expandable intraluminal metal stents could have been used to relieve her symptoms, despite a potentially fatal complication of stenting in this situation, including pressure necrosis leading to a bronchoarterial fistula. It was concluded that the cause of the tracheal compression may be the high pressure in the innominate artery, and that medical management aimed at optimal control of blood pressure would appear to be the most appropriate course.

\section{References}

1. Nashef SA, Dromer C, Velly JF, Labrouse L, Couraud L. Expanding wire stents in benign tracheobronchial disease: indications and complications. Ann Thorac Surg 1992; 54: 937-940.

2. Marines-Ballarin JI, Diaz-Jimenez JP, Castro MJ, Moya JA. Silicone stents in the management of benign tracheobronchial stenosis. Tolerance and early results of 63 patients. Chest 1996; 109: 626-629.

3. Tominaga R, Tanaka J, Kawachi Y, et al. Surgical treatment of respiratory insufficiency due to tracheobronchial compression by aneurysms of the ascending aorta and innominate artery. J Cardiovasc Surg 1988; 29: 413-417.

4. Nashiwaki K, Komatsu T, Shimada Y, Takeuchi E, Abe T. Severe tracheal compression caused by false aneurysm arising from the ascending aorta: successful airway management using induced hypotension and bronchoscopy. Anesthesiology 1990; 73: 1047-1049.

5. Philips GD, Smith EEJ, Millard FJC. Positional dyspnoea due to aneurysm of the thoracic aorta. Eur Respir J 1994; 7: 412-414.

6. Bron AO, Mensen EAM, Jijkman JH, Huyssmans HA, Aalbers R. Dyspnoea persisting after surgery for a vascular ring. Eur Respir J 1994; 7: 2257-2259.

7. Lindsay DC, Smith MC, McQuillan PJ, Jordan MB. Laryngeal compression and stridor as the presenting feature of ruptured thoracic aortic aneurysm. Report of two cases. J Cardiovasc Surg 1988; 30: 864-866. 